\title{
Os Sociólogos Antes de 1950
}

Victor Karady

\section{Resumo}

O objetivo do artigo é analisar a estratificação social dos praticantes de sociologia na França até 1950 e, a partir desses dados, buscar as razões que mantiveram a sociologia com status marginal no sistema universitário francês durante o período. Primeiro, considera-se a escola durkheimiana, apresentando dados que sustentam o porquê de a escola ter obtido êxito na concorrência com os demais praticantes da disciplina. Em seguida, argumenta-se que os durkheimianos formavam uma fração dominada dentro do grupo dominante e, por essa razão, não puderam subverter as regras do sistema universitário francês; ao contrário, eles foram assimilados por este e submetidos a desempenhar um papel relegado em relação às disciplinas tradicionalmente estabelecidas.

Palavras-chave: Sociologia francesa. Escola durkheimiana. Sistema universitário francês.

Para os professores e praticantes da disciplina, a história da sociologia francesa remonta à primeira metade do século XIX, marcada pela atividade de Saint-Simon e, sobretudo, de Auguste Comte, os quais criaram um conjunto de construçóes doutrinárias tão diverso que forneceu ideias por quase meio século a diversos grupos com pretensões científicas bem como a cursos e instituiçóes positivistas frequentemente prestigiosos. Dessa forma, foi possível associar a reflexão sobre a sociedade aos axiomas e aos métodos da filosofia positivista. No século XIX, o destino social do positivismo satisfez largamente aos critérios daqueles que acreditam que "[...] a institucionalização envolve a adoção de elementos ou objetos culturais específicos aos atores de um sistema social." e que "[...] para muitos domínios intelectuais, como as ciências sociais na França, ela significou a diferenciação de domínios e estruturas institucionais existentes, a criação de novas instituiçóes (organizaçôes profissionais, periódicos, centros

I Publicado originalmente em: KARADY, Victor. Les sociologues avant 1950. Regards Sociologiques, $n^{\circ} 22$, 200I, p. 5-22. Tradução de Romulo Lelis (USP) e revisão técnica de Marcia Consolim (Unifesp). Agradeço a Victor Karady pelos comentários e esclarecimentos a dúvidas em relação à versão original.

2 Professor da Central European University (CEU) e diretor de pesquisa Emérito do Centre National de la Recherche Scientifique (CNRS). 
de instrução) e, idealmente, a entrada no sistema universitário." (CLARK, 1973, p. 95). Sob o Segundo Império, o positivismo alcançou o status de legitimidade mundana e intelectual indiscutível, em particular com a fundação por Littré de um corpo permanente, La Philosophie Positive (1867); de um curso público dado por Lafitte desde 1869; de outro periódico, La Revue Occidentale (1877); da Société de Sociologie (1872); e, enfim, de um curso livre (1880) seguido de uma cadeira de "História da ciência" criada no Collège de France (para Lafitte e, desde 1904, para Wyrouboft). Contudo, durante sua vida, Comte - cujo Cours de philosophie positive (1830-1842) originou-se de conferências privadas feitas na semiclandestinidade das reuniôes de uma capela de fiéis -, náo conseguiu romper com a "conspiração do silêncio" da qual se considerava vítima. Na realidade, no final do século passado, em razão das afinidades ideológicas que ligavam os ideólogos da Terceira República ao cientificismo comtiano ${ }^{3}$, o movimento positivista só sobreviveu graças a algumas figuras-chave que continuavam a se beneficiar de simpatias oficiais, por vezes expressas com espetacular generosidade - a despeito do sucesso dos alunos franceses de Comte em estabelecerem-se em pé de igualdade com as disciplinas científicas legítimas e adentrarem no sistema institucional. Tal como uma verdadeira "Igreja" - que em vez de se integrar no sistema das ciências procurava substituí-las ou impor-se como método dominante -, os positivistas permaneceram, por razóes intelectuais, mas também por inflexibilidade, um movimento particular animado pela ambição de universalidade. Incapaz de realizar semelhante projeto por recusar resolutamente a neutralização ideológica, o positivismo estava condenado a desaparecer do campo de estudos legítimos e a vegetar sob a forma de cursos privados e cerimônias de capela. $\mathrm{O}$ movimento positivista fracassou completamente, sobretudo em seu esforço de organizar a sua reprodução ou em assegurar apoios de agências sociais preparadas para isso. Seja como for, apesar do colapso do movimento, o positivismo conservou na história da sociologia na França o status de referência capital em razão da obra de seus fundadores - os primeiros a postularem a unidade e a inteligibilidade do reino social.

3 Em 1904, o Ministério da Instrução Pública nomeou Gregoire Wyrouboff, antigo colaborador de Littré, para a cadeira deixada vaga pela morte de Lafitte. Essa nomeação foi escandalosa porque Wyrouboff era apenas o candidato em segunda posição, uma vez que o corpo professoral havia proposto para a primeira posição o historiador das ciências Paul Tannery, conhecido por suas simpatias católicas. 
A segunda tradição à qual remonta a sociologia no século XIX é a da pesquisa social iniciada por Le Play. Desde o início, ela teve menos pretensôes epistemológicas do que ambiçóes propriamente sociopolíticas. Personalidade oficial do Segundo Império - autor de Les ouvriers européens (1855) e de La réforme sociale (1864), escrito a pedido expresso de Napoleão III -, Le Play visava um objetivo abertamente apologético em suas monografias sobre família, de acordo com os preceitos do decálogo, isto é, de uma ordem social tradicional dominada pela autoridade "paternal" do patrão e dos chefes de família. Suas monografias sobre os orçamentos das famílias da classe trabalhadora atendiam a uma demanda social das fraçóes mais conservadoras das classes abastadas, as quais se viam ameaçadas pela ascensão das "desordens" sociais. Tendo em vista o controle cada vez menor das relaçôes sociais pelos detentores do poder, o estudo objetivista e empírico das classes populares - com foco na família, considerada a célula elementar da vida social - oferecia um meio de manipulação revestido da autoridade da ciência e, em consequência, considerado eficaz.

É assim que se explica o sucesso imediato e duradouro da Société d'Économie Sociale (desde 1856) e das Unions de la Paix Sociale, fortemente enraizadas na província. A escola de Le Play dotou-se rapidamente de órgãos de divulgação, de ensino e mesmo de pesquisa. Ela soube encontrar alianças institucionais na Académie des Sciences Morales et Politiques que, desde sua fundação (em 1832), dispunha de recursos destinados a promover e valorizar trabalhos de investigação por meio de prêmios temáticos. Contudo, a escola não só teve dificuldade em adquirir dignidade acadêmica completa (o que parece jamais ser independente de um projeto científico de valor universal), mas limitou-se deliberadamente a um papel a meio caminho entre a propagação de um corpo de ideias socialmente conservadoras e a divulgação de técnicas de coleta de dados sociais. Isso se deu em razão da estreiteza de sua problemática e da rigidez doutrinal quase-escolástica das soluçốes que a escola propôs a questôes abertas (como a sua tipologia das famílias e a explicação às vezes econômica, às vezes ecológica, da sociabilidade familiar dominante). Atualmente, apesar de historiadores da sociologia, na necessidade de ancestrais, terem descoberto na escola de Le Play os precursores franceses da sociologia empírica com base em analogias aparentes, não há na realidade nenhuma continuidade histórica 
observável entre o empreendimento de Le Play e as práticas estabelecidas que hoje são usadas em pesquisa. Na França, essa tradição de pesquisa não levou à instauração de práticas de investigação sociológica. Desde o fim do século passado, ela deixou de exercer qualquer influência na pesquisa ou mesmo de constituir uma referência digna, menos por suas implicaçóes ideológicas do que por suas fraquezas manifestas em seu próprio campo de estudo. A cisão do grupo - ocorrida em 1886 pela fundação (por estudantes dissidentes em torno de Demolins e Tourville) de uma nova revista, La Science Sociale - é, ao mesmo tempo, sua expressão e consequência. O novo grupo empenhou-se resolutamente na conquista de um mínimo de legitimidade científica ao refinar e operacionalizar o instrumento de análise grosseiro de Le Play, o que foi acompanhado pelo abandono da ação ideológica, do moralismo reacionário, das pretensôes abertas de um "ensino" social e da revelação de suas alianças de classe. Mas esses desenvolvimentos intervieram em uma conjuntura totalmente nova na última década do século XIX.

É por uma questão completamente diferente que seria preciso mencionar uma terceira tradiçáo intelectual, a dos estatísticos sociais e dos economistas, que poderia ter contribuído para a autonomização de um campo de estudos sobre a vida social. Contrariamente às tradiçóes anteriores, não se trata de uma escola de pensamento baseada em certa teoria do social, mas de um conjunto de praticantes diversificado: em primeiro lugar, os originários de disciplinas já parcialmente estabelecidas no sistema universitário e que gozam de legitimidade internacional (economistas); em segundo lugar, os técnicos em pesquisa para fins administrativos e sociopolíticos (estatísticos dos ministérios); em terceiro lugar, um tipo particular de pesquisadores de "problemas sociais" que atendem as aspiraçóes da burguesia liberal (os "higienistas" sociais). Nenhum desses especialistas, grupos ou movimentos pretendia (e não poderiam pretender) fundar uma nova disciplina, embora estivessem por vezes na origem de interessantes descobertas de fatos, de importantes inovaçóes técnicas, ou mesmo abrindo novas frentes de conhecimento dos fatos sociais. O empirismo de sua abordagem e a escolha de seu objeto correspondiam à definição de objeto social pelo senso comum das classes superiores e médias cultivadas - preocupadas com problemas práticos, isto é, econômicos, demográficos e de políticas públicas (para a 
domesticação das classes trabalhadoras) -, o que assegurou a esses praticantes uma boa recepção nos gabinetes de estudos ministeriais ou na Académie des Sciences Morales, que detinham os meios de pesquisa e, assim, restringiam as suas preocupações aos seus fins específicos. A economia política representa um caso particular por causa da resistência que as escolas profissionais de direito opuseram ao longo do século à sua institucionalização na universidade (que ocorreu somente com a criação de um doutorado em ciências políticas e econômicas associado a uma agrégation ${ }^{4}$ especializada), ainda que essa disciplina tenha sido precocemente organizada de uma forma profissional (pois assegurava carreiras na alta administração e no setor privado). Ela também permaneceu, em grande parte, tributária de um problema definido pela demanda social que a tinha suscitado. Assim, seu próprio sucesso relativo - que não é inteligível sem que se considere o caráter pragmático de seu método e a especificidade de seu tema - contribuiu para limitar as ambiçóes desses praticantes com o objetivo de excluir qualquer projeto de ciência social geral sobre o conjunto dos fatos sociais.

Evidentemente, as condições sociais para a formulação de tal projeto não estavam reunidas antes dos anos 1890, quando surge uma série de movimentos intelectuais importantes, organizados em sociedades científicas, revistas ou centros de instrução específicos nos quais ele germinava. Basta indicar essas etapas para deixar claro que a verdadeira institucionalização da sociologia começou somente no fim do século, depois dos antecedentes que acaba-se de assinalar. Para se ater provisoriamente aos índices mais aparentes, pode-se observar uma série de criaçóes de revistas, órgãos de escola, periódicos de vocação profissional, periódicos de informação destinados ao grande público - como La Science Sociale, em 1886, a Revue Internationale de Sociologie, em 1893, os Annales de l'Institut International de Sociologie, em 1893, o Année Sociologique, em 1897 e, enfim, as Notes Critiques de Sciences Sociales, em 1900 - que se juntaram à já antiga $L a$ Réforme Sociale e às revistas temáticas especializadas, tais como o Journal de la Société de statistique de Paris, a Revue d'Économie Politique e o Journal des Économistes. Isso sem falar dos periódicos eruditos dedicados a campos

4 A agrégation é um concurso nacional de acesso aos cargos de professor no ensino secundário (liceu) ou no ensino superior. A aprovação nestes concursos confere o título de agrégé (N.T.). 
específicos de estudo, cujo status autônomo foi admitido mesmo antes desse período (história das religióes, antropologia, etnografia, folclore), incorporados posteriormente como partes de uma disciplina de síntese superior pela dinâmica da teoria durkheimiana. Quaisquer que sejam as diferenças que as separam, a característica comum dessas revistas aparece no escopo dos temas tratados - que, ao contrastar com a organização temática das disciplinas estabelecidas, limitando-as ou extravasando-as, rompem com todas as tradiçóes anteriores. Nota-se que a maior parte dessas novas publicaçôes veiculou, em graus diversos, uma redefinição das fronteiras e, por implicação, uma redefinição do conteúdo da disciplina à qual se dedicavam. Além disso, à mesma época são publicados, de maneira crescente, os primeiros manuais de "sociologia", e surgem rubricas "sociológicas" em revistas universitárias de prestígio, como a Revue de Métaphysique et de Morale (1893). Nesse momento também são fundados os primeiros cursos universitários mais ou menos expressamente dedicados à "ciência social": primeiro o curso de Durkheim em Boudeaux (1887), transformado em cátedra em 1896, e em seguida os cursos de Bouglé na Faculté des Lettres de Montpellier e de Bertrand na Faculté des Lettres de Lyon. Acrescentem-se os cursos ministrados nas Grandes Escolas Nacionais e em instituiçôes privadas (École Libre des Sciences Politiques, Facultés des Lettres et de Droit Catholiques), mas sobretudo os cursos públicos organizados sob a égide do Collège Libre des Sciences Sociales (1895) e da École des Hautes Études Sociales (1900). A partir daí, foram defendidas uma dezena de teses de doutorado ligadas à nova disciplina, sobretudo na área de estudos filosóficos, mas por vezes também na de história social ou de geografia humana - fato sem precedentes nas faculdades de letras francesas ${ }^{5}$. No fim do século, ainda que a própria noção de ciências sociais ou de ciência social prevaleça sobre a noçáo de sociologia - que muitas vezes aparece apenas como uma especialidade menor, dominada em relação às disciplinas estabelecidas (economia política, pedagogia etc.) -, tudo leva a atestar que, na última década do século XIX, ocorreu uma reorganização decisiva do campo institucional, em particular das instâncias de legitimação científica, que conduziu progressivamente ao reconhecimento da autonomia de uma

5 As faculdades de letras compreendiam os estudos universitários em filosofia, letras e ciências humanas (N. T.). 
nova disciplina sintética sobre fatos sociais. Essa ebulição de inovações institucionais não será encontrada até o período que se seguiu à Segunda Guerra Mundial.

O caráter aparentemente orquestrado e temporalmente concentrado desse movimento institucional poderia levar a atribuir-lhe uma unidade de inspiração que não possui. No presente estudo, partimos da hipótese de que esse movimento é irredutível a uma análise de conjunto à medida que minimiza sua estratificação interna - isto é, as relaçôes de competição, interdependência, dominação ou relegação entre suas unidades constitutivas (grupos, equipes editoriais, escolas de pensamento ou mesmo autores individuais) -, criando um impasse a respeito das bases sociais dessas relaçóes (atividades sócio profissionais, formação, vínculos de classe e interesses de grupo) ou negligenciando as diferenças entre suas práticas científicas (como temas preferenciais, métodos de trabalho ou o universo das referências). $\mathrm{E}$ isso porque tais fatores proporcionam aos diferentes grupos de praticantes possibilidades variadas de contribuir para a legitimação da sociologia como disciplina no sistema de disciplinas estabelecidas.

\section{A estratificação dos meios sociológicos}

É preciso, portanto, estabelecer alguns indicadores que permitam situar esses grupos de "sociólogos" no campo social em geral, no campo intelectual e, mais especificamente, no campo universitário, a fim de explicar a configuração das chances de sucesso ou de fracasso observadas (ou do poder de imposição de sua prática científica como a única legítima) por meio de outras características, como a condição social, a posição intelectual ou a prática científica.

Esta pesquisa baseia-se, primeiramente, no estudo de uma amostra amplamente selecionada e em seguida reduzida aos colaboradores das principais revistas especializadas. A amostra originalmente considerada deveria cobrir de forma exaustiva as seguintes populaçóes: colaboradores de periódicos sociológicos; professores de ciências sociais na Universidade e em instituiçóes privadas; doutores e outros diplomados (bem poucos) nessas disciplinas; enfim, os autores de resenhas em revistas especializadas ou presentes nas bibliografias tópicas contemporâneas. Se essa ampla amostra teve que ser abandonada e substituída pelo seu núcleo foi porque se tornou 
impossível reunir as informações indispensáveis sobre uma fração estatisticamente significativa dessa população. Por outro lado, a amostra reduzida, mais bem conhecida, tem a desvantagem de levar em conta apenas as subpopulaçóes visivelmente mais distintas, cuja produção consta das revistas - o que exclui os meios marginais em relação às revistas e leva a minimizar as colaboraçôes (algo variável de uma revista para outra), ou seja, a tratar esses agregados ad hoc como agrupamentos realmente integrados e, por essa razão, passíveis de uma análise global. Assim, constatamos que apenas os colaboradores de L'Année Sociologique formaram uma equipe, no sentido de que a maioria deles contribuiu regularmente para uma obra comum, ao passo que os outros grupos são constituídos majoritariamente por colaboradores ocasionais. Em relação ao número de colaboradores, o tamanho dos grupos - reduzido entre os durkheimianos e mais ou menos amplo entre os demais - fornece uma indicação aproximada do seu grau de homogeneidade: um conjunto muito grande de autores dificilmente poderia pretender a mesma coesão intelectual do que uma equipe de tamanho restrito.

Contudo, essa fragilidade da amostra esconde também sua principal virtude, que é permitir opor os grupos de autores mais claramente identificáveis, por suas diversas características de condição e de posição, a partir dos principais critérios de estruturação do campo. Além disso, a subamostra oferece a vantagem de ser formada em torno dos autores mais representativos dessas tendências e, portanto, mais conhecidos e identificáveis, ao invés de um número maior de praticantes de status incerto, colaboradores ocasionais de revistas, membros passageiros de escolas de pensamento, palestrantes em uma sessão de uma sociedade científica. Assim, é provável que os dados coletados refiram-se às fraçóes da população mais propriamente identificáveis à escola de pensamento, às tradiçóes intelectuais ou aos grupos de interesse profissional que as revistas representam - mesmo que as subamostras efetivamente observadas em cada revista constituam apenas uma pequena fração das populaçóes afins (cerca de um quarto dos autores de La Science Sociale, três quintos dos autores de La Réforme Sociale). Algumas das fontes exploradas - necrológios de revistas, artigos biográficos de dicionários e notas bibliográficas - correspondem indiretamente à preocupação de definir subgrupos representativos de agrupamentos 
maiores. Em outras palavras, para uma parte da amostra, os princípios da escolha das subamostras são idênticos às condições de produção das informaçóes pesquisadas.

\section{Vínculos sociais e interesses coletivos}

A principal característica social de todo grupo intelectual pode ser diretamente identificável à sua atividade sócio profissional e, consequentemente, à sua posição no sistema de classes, à medida que sua produção simbólica, científica, literária e pedagógica se realiza por meio de enquadramentos profissionais - de modo que sua atividade específica determina sua posição na estrutura social. No caso da sociologia, no período estudado ela jamais alcançou um estágio suficiente de profissionalização que a identificasse a um ofício socialmente reconhecido. Nos diversos meios de sociólogos, ela sempre constituiu, no melhor dos casos, uma atividade secundária ou uma disciplina complementar e, no pior, um passatempo de prestígio ou uma ocupação enquadrada em uma categoria tão heterogênea quanto a da produção ideológica voltada às necessidades das classes e de grupos de interesse variáveis. Essa proposição continua a ser amplamente válida mesmo para os casos-limites mais conhecidos, isto é, para os sociólogos universitários, dado que na maioria das vezes eles não foram titulares de um posto de ensino claramente voltado à sociologia ou, quando o foram, podiam dedicar-se a ele apenas em tempo parcial. Assim, a dimensão fundamental da condiçáo do sociólogo, antes de 1940, estava circunscrita por um fato primordial: sua não profissionalização ou profissionalizaçáo incompleta. Isso também significa que os status (de amador ou de erudito profissional; de pesquisador e teórico ou de vulgarizador; de cientista ou de diletante etc.) não obedeciam a critérios de definição unívocos como no caso das disciplinas científicas profissionalmente estabelecidas (direito ou economia política), cuja prática estava associada ao exercício de ofícios (sejam profissôes liberais, sejam funçôes universitárias). Mais precisamente, no caso da sociologia, a hierarquia intelectual não correspondia, ideal ou virtualmente, a uma hierarquia de status institucional. Isso significa ainda que a sociologia não possuía o mesmo grau de homogeneidade ou de unidade em termos de distinçóes estatutárias, práticas, valores ou normas científicas vigentes em outros campos de estudo. Ao contrário, a sociologia 
era fragmentada e segmentada, o que permitia, no limite, que autores envolvidos no mesmo campo de pesquisa se ignorassem ou não se reconhecessem uns aos outros como inseridos em um mesmo campo. A raiz última desse estado de coisas pode ser buscada nos vínculos sócioprofissionais extremamente variáveis que marcam os diferentes meios sociológicos. Dessa forma, eles não podiam deixar de referir sua prática científica a normas de grupos particulares e opostas entre si. Assim, a atividade sociológica, independentemente da maneira como era concebida, devia assumir funçóes coletivas distintas em cada um desses meios fragmentados.

Uma medida geral da estratificação social nos meios sociológicos é dada pelas categorias sócioprofissionais. No entanto, essa medida um tanto grosseira permite algumas distinçóes fundamentais. Em particular, ela salienta os vínculos quase inteiramente universitários dos durkheimianos, entre os quais todas as outras posiçóes e funçôes sociais são excepcionais. Os autores da Revue Internationale des Sciences Sociales ${ }^{6}$ são nitidamente muito menos estabelecidos nas profissóes docentes e, muito embora esse seja o caso de mais de metade deles, os outros se dividem entre a alta função pública, as posições políticas e, em menor grau, as profissóes liberais. Grosso modo, o mesmo se aplica ao grupo residual (e muito pouco estudado) dos autores de Notes Critiques. Em contrapartida, os dois subgrupos formados pelos alunos de Le Play se distanciam dos demais grupos por uma proporção minoritária de professores e pela presença notável de grandes contingentes da burguesia empresarial e do alto escalão do Estado, além de políticos, profissionais liberais e profissóes intelectuais livres (jornalistas, artistas, editores etc.). Assim, em termos de posição de classe, a composição sócioprofissional dos sociólogos revela diferenças internas importantes que podem ser expressas sucintamente da seguinte forma: a Escola Sociológica ${ }^{7}$ foi recrutada preferencialmente nas elites intelectuais social e politicamente dominadas, enquanto os outros grupos foram formados pelas fraçóes das classes dominantes associadas a certas fraçóes, sobretudo católicas, da elite intelectual.

6 O nome correto da revista é: Revue Internationale de Sociologie - fundada em 1893 e dirigida por René Worms (N. T.).

7 Ou seja, a Escola Sociológica Francesa - como ficou conhecido o grupo em torno de Durkheim (N. T.). 
Essa análise pode ser confirmada e especificada a partir de uma série de outros dados coletados sobre os mesmos grupos ou sobre certas comunidades afins. Considerando-se apenas as profissóes intelectuais ou docentes, percebe-se que a oposição entre os durkheimianos e seus concorrentes é mais profunda, em termos de posição de classe, do que havia sido estimada acima. Todos os colaboradores de L'Année Sociologique exerceram uma profissão intelectual em algum momento de suas carreiras, bem como pertenceram, em sua maioria, ao ensino público - em particular às seçóes literárias ${ }^{8} \mathrm{da}$ antiga Universidade e, para dois terços do total, às faculdades de letras. Em nenhum outro grupo os professores dessas faculdades constituem maioria. Observa-se uma grande proporção de juristas das faculdades de direito público entre os colaboradores da Revue Internationale de Sociologie, ao passo que as escolas derivadas de Le Play se distinguem por contingentes relativamente importantes de professores de faculdades católicas e de profissóes intelectuais livres (entre um quarto e quase um terço), cuja proporção ultrapassa largamente a de membros do ensino público. A composição profissional dos colaboradores de Notes Critiques, dos Annales e dos membros do Institut Français de Sociologie remonta àquela de L’Année, prova indireta do parentesco estreito, senão da identidade, desses grupos. Ao qualificar os primeiros de universitários "literários" e associar os segundos ao polo intelectual das classes superiores, essas informaçôes suscitam uma ruptura dicotômica dos meios sociológicos, que opóe os durkheimianos e o grupo que lhe é assimilável ao resto da população profissional. Com efeito, ao conhecer o público das faculdades livres ou das faculdades de direito, bem como a composição das "outras profissóes", não há risco de cometer erro grave ao considerá-los clérigos das classes dominantes.

Essa distribuição um tanto dicotômica pode ser especificada se considerarmos a escolaridade superior dos membros dos diversos meios. A oposição entre os durkheimianos aos demais grupos (Tabela 1) pode

8 Os termos "literário" e "literato", no caso deste artigo, abarcam os cursos ou indivíduos provenientes das "áreas de humanas", e que à época compreendiam três grandes áreas: filosofia, história e letras. Assim, o título de doutorado em qualquer dessas três áreas era denominado "doctorat ès lettres", ou seja, referente às faculdades de letras e não a uma disciplina específica. Por isso os termos "literário" e "literato" não devem ser associados a pessoas ou atividades da área de literatura - até porque, no caso dos durkheimianos, a maioria provém da área de filosofia (N.T.). 
ser observada pela proporção de portadores de diplomas ou de títulos das faculdades de letras em ambos os grupos - duas vezes maior no primeiro comparativamente aos segundos. Essa proporção se inverte se comparamos os detentores de diplomas concedidos pelas faculdades de direito (tanto das faculdades de Estado quanto das faculdades privadas) nos dois grupos - e a desproporção nesse caso parece muito mais pronunciada (chegando a mais do que o triplo). Além disso, os grupos concorrentes de L’Année Sociologique compreendem uma parcela importante de diplomados das faculdades científicas e médicas (que alimentam as profissóes liberais), bem como os Chartistes ${ }^{9}$ e os teólogos (que juntos representam cerca de um sexto dos alunos de Le Play). Ainda mais notável é a grande proporção de não diplomados ou de desconhecidos (infelizmente impossível de ser distinguidos empiricamente entre si). Apesar de tudo, esse fato pode ser interpretado como a marca das classes abastadas rentistas, resguardadas das constrições da obtenção de diplomas (mesmo que enviassem seus filhos para a faculdade), pois na maioria das vezes não exerciam nenhuma atividade profissional. Com efeito, uma vez que nosso período de observação ainda não havia conhecido a superescolarizaçáo das classes altas no ensino superior, o exercício do poder econômico ou político não dependia do mesmo tipo de legitimação por competência escolar como o que foi desenvolvido no período subsequente. Como se sabe, essa carência relativa de diplomas introduzia diferenças acentuadas entre a burguesia parisiense e urbana e os proprietários da província e rurais. Ora, dispomos de alguns dados que sugerem que os meios sociológicos não durkheimianos, particularmente os leplayistas, foram singularmente marcados por seus vínculos com as classes dominantes da província.

9 Chartistes são os alunos da École Nationale des Chartes, especializada em ciências auxiliares à História, como estudos patrimoniais e de arquivologia (N. T.). 


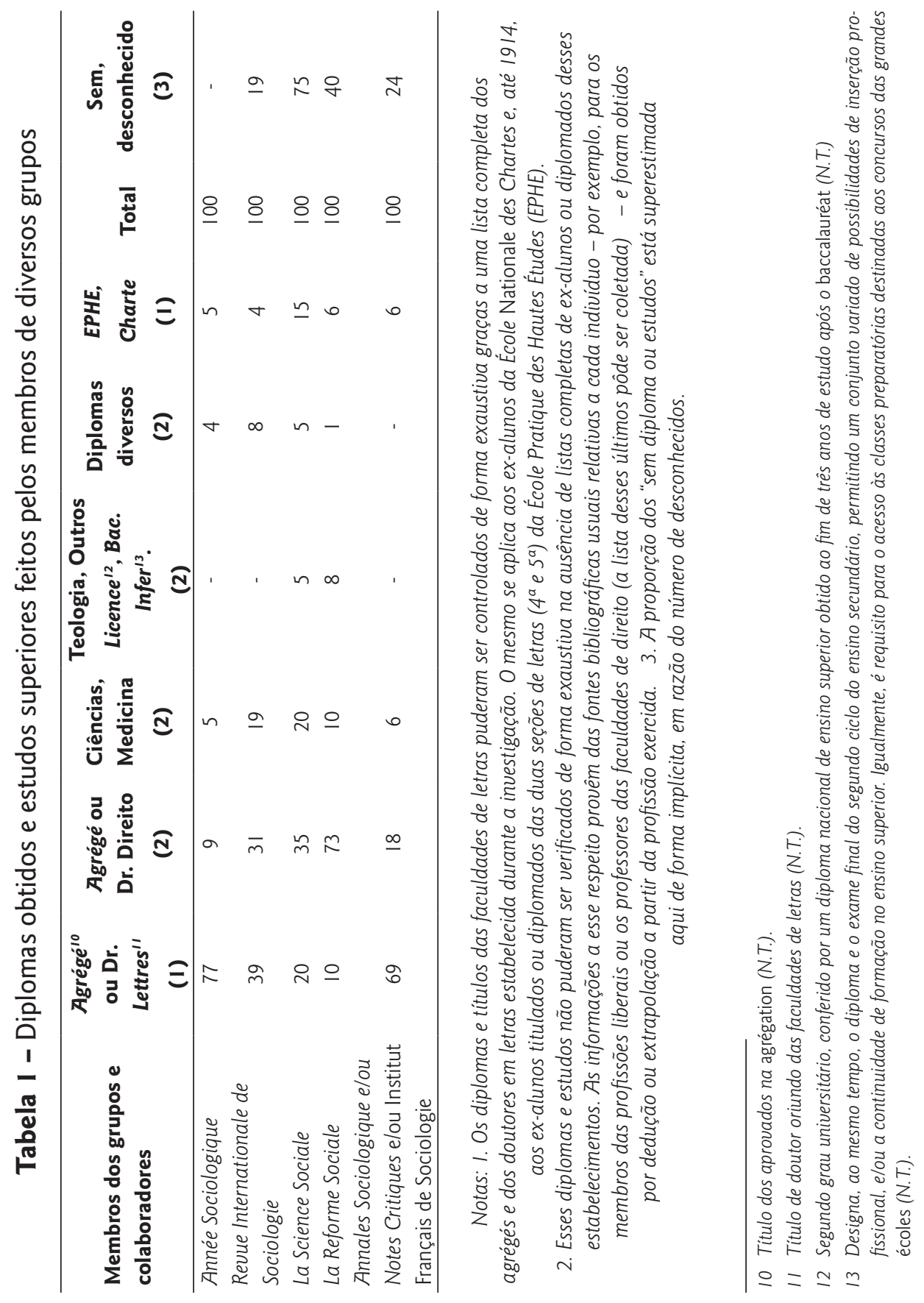


Assim, as duas sociedades de estudos sociais originárias do ensino de Le Play se estabeleceram predominantemente fora de Paris (na proporção de três quartos dos membros). Na sociedade dos leplayistas ortodoxos, mais conhecida, os membros parisienses se distinguem por um contingente relativamente alto de intelectuais propriamente ditos (um quinto), correlativamente a um contingente fraco de eclesiásticos e de grandes proporçôes de cadres $^{14}$ e de funcionários públicos superiores. Entre os provincianos da mesma Sociedade, nota-se a participação massiva da aristocracia e da nobreza. A Société de la Science Sociale apresenta um perfil semelhante, embora com uma proporção ainda maior de nobres e de clérigos. Tudo leva a crer que os membros franceses das sociedades científicas, sob a égide da Revue Internationale de Sociologie (Société de Sociologie de Paris e Institut International de Sociologie), ofereceriam um quadro de sua composição sócioprofissional (se pudéssemos dispor dos dados a esse respeito) intermediária entre durkheimianos e leplayistas. É impossível mencionar elementos de comparação com L’Année Sociologique no caso dos públicos maiores, à margem desses meios, que tiveram pouco envolvimento intelectual na prática sociológica e que se dividiam em grande parte entre ouvintes, leitores potenciais e assinantes cuja contribuição permaneceu exclusivamente financeira. Em resumo, as observaçôes realizadas até agora permitem dizer que, nos meios sociológicos anteriores a 1940, a hierarquia intelectual corresponde a uma espécie de inversão da hierarquia dos vínculos sócioprofissionais dos grupos, ou ainda, que a escola de pensamento dominante é recrutada nas fraçóes politicamente e economicamente dominadas das classes dominantes. Essa constatação seria de menor interesse se tratássemos de uma disciplina profissional na qual os não profissionais tendem, necessariamente, a tornar-se intelectualmente marginais. Mas, ainda assim, seria crucial analisar as condiçóes sob as quais a Escola Sociológica Francesa, associada às faculdades de letras, pôde se impor e fazer frente aos concorrentes estabelecidos nas faculdades de direito públicas e privadas, ou seja, como os "bolsistas" da Universidade prevaleceram sobre os "herdeiros”. Em grande parte, o destino histórico da sociologia francesa está ligado a esses fatos.

14 Termo empregado para designar cargos administrativos no setor público ou privado (N.T.). 


\section{Vínculos socais, posições universitárias e propriedades intelectuais}

A oposição entre, de um lado, os literatos e, de outro lado, juristas e economistas, é uma das mais antigas e acentuadas entre as que dividiram os meios sociológicos. Encontramos seus ecos no célebre debate entre Tarde e Durkheim, mas suas raízes remontam ao próprio surgimento da sociologia nas faculdades de letras, desencadeando a imediata hostilidade de certos juristas. Pelo fato de a sociologia ter tomado por objeto de estudo o direito, assimilando-o aos outros fatos sociais, eles viram nisso uma verdadeira violação de seu ensino e um questionamento de sua competência. Segundo Maurice Hauriou, o primeiro professor da faculdade de direito a fazer um curso de "sociologia", isso poderia colocar em perigo "as relaçóes entre as nações" e "as relações entre as classes". É interessante citar Hauriou, uma autoridade na época, porque seu sintomático artigo ilumina o princípio de oposição entre sociólogos, juristas e "literários". De acordo com Hauriou, o direito é uma "arte” que está “[...] baseada na hipótese de que as relaçóes sociais devem ser analisadas por meio de vontades expressas por pessoas responsáveis." (HAURIOU, 1893, p. 3-4). Em outras palavras, essas relaçôes estão ligadas ao livre arbítrio dos agentes sociais e, por sua vez, o determinismo universal é um sistema filosófico indemonstrável e inútil para a sociologia (como para qualquer outra ciência), que deveria se contentar com leis científicas limitadas (a exemplo das "leis da imitação", de Tarde). Segundo Hauriou, se a sociologia é uma ciência, a ciência é sempre inferior à arte - no caso, o direito. Essa petição de princípio é compreensível apenas quando associada às relaçóes objetivas mantidas entre as faculdades de direito e as faculdades de letras, ou seja, entre as escolas profissionais, de um lado, e os estabelecimentos de livre erudição ou de cultura geral, de outro lado. A função das faculdades de direito, de preparar para a profissão proposta para o manejo do poder social judiciário, mas também, indiretamente, político e econômico, correspondia a exigências eminentemente práticas. Ao contrário, as faculdades de letras, voltadas a formar exclusivamente uma elite intelectual livre e de professores, não assumiam qualquer função profissional e podiam, portanto, promover uma ideologia de erudição desinteressada. A oposição entre a arte social, concebida no vocabulário da época como técnica, e a ciência social, entendida como função do 
conhecimento, engloba, assim, a oposição genérica entre dois subsistemas do ensino superior. Precisamente por causa de suas funçóes sociais distintas, contribuíram para canalizar a reflexão sociológica nascente para diferentes temas, domínios de estudo, concepçóes de objeto e teorias do social.

Essa oposição entre os vínculos universitários é ainda maior à medida que é reforçada pelos efeitos diversos dos interesses coletivos dos meios e das classes sociais, aos quais estavam ligados, como vimos, os principais grupos de praticantes da sociologia por suas origens. Sem remontar a esses interesses coletivos (cuja ação mereceria um estudo particular), devemos entender que as faculdades de direito nunca deram espaço de fato para o ensino sociológico antes da Segunda Guerra (ou mesmo depois). Ou seja, a prática sociológica de juristas e economistas não teve o mesmo tipo de institucionalização que a dos "literários", permanecendo nesse período uma prática de amadores em boa parte externa às funçóes universitárias. Esse fato merece ser assinalado como um dos paradoxos na história da sociologia francesa: o pensamento sociológico em geral e a teoria durkheimiana em particular determinaram como objetivo principal, desde o início, a interpretação das instâncias de disciplina (ou controle) social entre as quais o direito representa a forma mais elaborada; e antes da revolução epistemológica dos anos 1890, a definição dos "problemas" e mesmo do fato social era um dos principais temas de estudo das faculdades de direito, em particular o sistema jurídico, a economia política e a organização política propriamente dita. Contudo, em razão do enraizamento prático da reflexão que elas induziam, essa proximidade ou quase identidade dos temas de preocupação, em vez de promover a sociologia nascente, só poderia paralisá-la. Assim, a rica e variada literatura produzida por professores de direito e seus alunos, na virada do século e posteriormente, jamais conseguiu realizar a menor ruptura de ordem epistemológica ou metodológica em relação ao jornalismo sociopolítico sério. A Revue Internationale de Sociologie pode ser considerada como o resultado e a representante desse movimento de interesse de amadores cultivados e bem informados, dotados da cultura sociopolítica promovida nas faculdades de direito públicas. La Réforme Sociale poderia ser definida como a expressão do interesse sociopolítico da burguesia e da nobreza cultivadas formadas nas faculdades de direito católicas. Sem dúvida, os professores e diplomados dessas faculdades 
constituíam apenas uma fração do público de leplayistas, mas era a fração modelo, representativa e militante.

Essas divergências explicam em grande medida a ignorância voluntária ou o desconhecimento que as escolas de ambos os lados testemunharam entre si. Na visão de sociologia dos durkheimianos, os juristas ocupavam uma parcela restrita, o que se percebe ao ver que eles citavam preferencialmente os poucos professores de direito de sua própria obediência intelectual. Na mesma linha de raciocínio, podemos notar os entraves que os juristas impunham regularmente sobre a sociologia nas faculdades de letras. Por exemplo, em seu relatório geral sobre o ensino das ciências sociais na França (1900), Charles Gide menciona a sociologia ostensivamente no décimo segundo e último lugar, insinuando que essa disciplina "[...] não é ensinada em nenhum lugar sob a forma de curso regular.”, para logo acrescentar que esse estado de coisas "[...] pode ser justificado pelo caráter muito mal definido dessa disciplina, que não ouso chamar de ciência." (GIDE, 1902, p. 83). Esse tipo de ignorância calculada e de difamação, amplamente utilizada durante toda a fase não profissional do desenvolvimento das ciências sociais, só foi possível graças ao caráter cindido das instituiçôes de vínculo que podiam servir de referência legítima e de garantia (evidentemente totalmente simbólica) de cientificidade.

Embora os dois tipos de faculdade constituíssem de alguma forma os protótipos históricos dessas instituiçôes, as várias sociedades científicas assumiram uma função no fundo idêntica, qual seja assegurar uma maior legitimidade científica onde ela faltava objetivamente. Dadas as relaçóes de forças intelectuais desfavoráveis, quanto mais faltava uma escola de pensamento, mais sentia-se a necessidade dessa garantia. Isso explica a multiplicação de fundaçóes institucionais secundárias que caracteriza grupos intelectualmente dominados (sociedades científicas, congressos regulares ou ocasionais, participação em eventos acadêmicos estrangeiros, cursos públicos especiais, periódicos de escola e até estabelecimentos escolares). Em contrapartida, os durkheimianos nunca recorreram a uma institucionalização tão particularista e jamais se aproximaram de grupos de referência que não constituíssem sociedades científicas universitárias originárias da Sorbonne - ou seja, o grupo de seus pares. Essas sociedades eruditas, lembremo-nos, não tinham nada em comum com as instituiçôes análogas dos 
agrupamentos sociológicos, em razão de seu caráter exclusivamente profissional, seletivo (não faziam proselitismo e cooptavam de seus membros segundo critérios de competência) e fechado (com limitação rigorosa do número de membros).

Embora os durkheimianos tentassem estabelecer uma identidade de escola de pensamento apenas por meios intelectuais - ao reclamar uma inspiração científica fornecida pela teoria social de Durkheim -, eles detinham legitimidade suficiente não por causa de seus particularismos, mas por causa do espaço intelectual que eles ocupavam, independentemente de sua pertença a uma escola de pensamento. Em face de seus concorrentes potenciais, a posição excepcionalmente forte dos durkheimianos em órgãos científicos legítimos mostra que ela diz respeito a uma verdadeira estratégia de sucesso coletivo. Com efeito, Durkheim sempre considerou a fundação de revistas especializadas como "prematuras" - como a RIS ou seu corolário, os Annales Internationales de Sociologie, cujo exemplo ele se recusava seguir; da mesma forma, ele jamais pensou em formalizar a existência de sua equipe com a criação de uma sociedade científica, pois uma disciplina de status marginal nada ganharia com o isolamento particularista. Ao contrário, a consolidação e o reconhecimento de laços estreitos com disciplinas legítimas bem como o acesso aos órgãos representativos de difusão ofereciam todas as vantagens para suprimir o caráter marginal vinculado à disciplina como um todo e aumentar seu prestígio. A supressão, desde 1906, das memórias originais de L’Année Sociologique correspondeu claramente a essa estratégia, orientando convenientemente a produção "dogmática" da equipe para as revistas legítimas das disciplinas afins. Sem dúvida, como a recepção filosófica do durkheimianismo certamente testemunha, inserir o público não especializado (ou especializado em outra área) de uma revista filosófica nos problemas da teoria sociológica era correr o risco de todos os mal-entendidos e incompreensóes. Um estudo detalhado das reaçóes universitárias a Durkheim, dentro da própria Sorbonne, por parte do círculo de seus amigos ideológicos (Lucien Herr) ou mesmo da equipe de L'Année revelaria a amplitude das críticas quase unânimes que ele teve que enfrentar. Mas, certamente, isso não era o essencial das relações escrupulosamente mantidas pelos durkheimianos com as instâncias de legitimação universitárias. Para eles, a questão consistia principalmente em ser admitidos 
(mas não necessariamente bem recebidos), o que significava, acima de tudo, ser admitido como igual, provido de legitimidade semelhante àquela detida pela instância de recepção.

Podemos perceber a manifestação mais visível, senão a mais fundamental, da fragmentação da prática sociológica por diversos "interesses" coletivos por meio das diferenças temáticas dos trabalhos segundo as escolas de pensamento. Ao opor os durkheimianos aos demais grupos, notamos que se apresenta claramente um contraste: de um lado, os objetos de estudo desprovidos de atualidade histórica, "desinteressados" e cientificamente construídos e, de outro lado, os problemas sociais da atualidade, estudos "aplicados" e objetos previamente construídos. Essa oposição tão aparente poderia ser explicada e interpretada em profundidade por um estudo preciso das técnicas de investigação, dos métodos de análise, das categorias de pensamento aplicadas (sistema de noçóes), dos universos referenciais e, sobretudo, dos pressupostos teóricos da pesquisa.

$\mathrm{Na}$ realidade, independentemente do índice adotado, todas as variáveis objetivas que definem os caracteres intelectuais, ideológicos, científicos ou sociais dos grupos contribuem para mostrar que as diferenças são sistêmicas e que é necessário procurar nesse sistema de diferenças a origem dos diferentes destinos dos grupos. Não é possível analisar em detalhe aqui, por exemplo, os vínculos ideológicos dos grupos, mas uma observação superficial permite opor novamente os durkheimianos (dreyfusards, próximos do socialismo de Jean Jaurès ou de diversas tendências radicais e socialistas; anticlericais e favoráveis à separação da Igreja e do Estado em 1905; promotores ou beneficiários das reformas escolares republicanas; hostis à manutenção da primazia dos estudos clássicos nos programas secundários etc.) aos seus concorrentes, aos quais podem ser mais ou menos sistematicamente atribuídas às posiçóes contrárias. Ora, essas posiçóes estavam associadas a gêneros particulares de concepção sobre o social, mas também constituíram, por vezes, a condição (ou a condição de possibilidade) de certos tipos de pesquisa. Para mencionar apenas um exemplo patente, sabemos qual foi o peso dos universitários de origem judaica na equipe durkheimiana, particularmente entre aqueles que lançaram os fundamentos de uma teoria sociológica da religião (Durkheim, Mauss, Hertz). Não podemos entender o nascimento da sociologia da religiáo sem levar em conta a 
relação desobrigada que seus fundadores mantinham com o culto. Por si só, essa distância relativa (que exclui tanto a militância antirreligiosa quanto a apologia ou o proselitismo, isto é, todas as atitudes sobredeterminadas pela experiência do compromisso religioso ou da ruptura com tal compromisso) parece ter permitido o tratamento objetivista dos fenômenos religiosos próprio à abordagem durkheimiana. Esse caráter pode ser demonstrado com a ajuda de elementos significativos dessa abordagem: de um lado, uma espécie de profanação constante dos cultos monoteístas, sistematicamente reduzidos às mesmas funçóes sociais das religióes arcaicas (explicação do superior por "inferior"); de outro lado, a hipóstase teoricamente fundada dos cultos como base da coesão coletiva (sagrado e profano opondo-se como o coletivo e o individual). Parece fazer sentido que uma relação engajada ou "complexa" com a cultura religiosa, manifestada pela maioria dos membros dos grupos concorrentes, interditava semelhante abordagem, aparentemente desvinculada das contingências históricas.

\section{A sociologia universitária}

Emerge das análises precedentes - em especial do exame das relaçóes de força intelectuais e a despeito das contribuiçôes críticas e práticas dos grupos concorrentes - que o destino da sociologia francesa foi (até a Segunda Guerra) moldado essencialmente pela equipe durkheimiana, cujos laços estreitos com as faculdades de letras havíamos constatado. Por conseguinte, é necessário rever brevemente a história da institucionalização da sociologia na universidade e extrair liçôes sobre as condiçôes e os limites de inscrição de uma nova disciplina em estabelecimentos fortemente estruturados e adaptados a funçóes que ela não poderia desempenhar. Esse processo apresenta tantas ambiguidades e incompletudes que até a "imagem de Épinal" e de seu passado coletivo idílico - que atrai os historiadoressociólogos aficionados - foi deformada projetando-se sobre ela desde um crescimento contínuo até seu advento triunfal.

Tudo leva a pensar que essa representação da disciplina deve muito à imagem pública de Durkheim que, no auge de sua carreira, tornou-se uma espécie de personalidade oficial do establishment intelectual parisiense, unindo a força de um discurso profético (com a promessa de salvação pela ciência) à influência extraída de posiçôes estratégicas do poder universitário 
(com o direito de vislumbrar as carreiras das faculdades de letras) - o que não seria possível sem a conjuntura universitária e ideológica resultante da vitória dreyfusiana e a consolidação da renovação da Sorbonne. Assim, devido ao espaço intelectual e posicional que ele ocupava, esse personagem estava exposto a todos os ataques ou às críticas da direita (ou dos conservadores), ao mesmo tempo em que concentrava todas as adesóes à causa da renovação universitária, ao "espírito" científico, positivista e liberal. De acordo com essa apresentação possivelmente muito esquemática do papel social desempenhado pelo mestre da escola sociológica, compreendese que os autores, demasiadamente pressionados, logo assimilaram pura e simplesmente a posição de Durkheim na Universidade àquela da disciplina que ele representava. Convém examinar o lugar real dos durkheimianos e das ciências sociais nas faculdades para esclarecer o debate e captar seu verdadeiro objeto - as condições da institucionalização da sociologia.

À primeira vista, se levamos em conta as propriedades de posição no sistema universitário, nada invalida a constatação que os durkheimianos ocupavam, como universitários, posiçôes particularmente importantes: eles representavam a fração dominante da elite universitária com um grande contingente de ex-alunos da École Normale de Paris (Durkheim, Fauconnet, Hubert, Simiand, Hertz, Bourgin, Davy etc.) - verdadeiro viveiro e base de recrutamento da equipe na virada do século. Além disso, eles concentravam uma proporção majoritária de professores de filosofia, praticantes de uma disciplina que sempre esteve no topo da hierarquia das disciplinas escolares - o que não só assegurava aos durkheimianos o prestígio de uma formação das mais nobres e difíceis, mas também os situava objetivamente no âmbito da disciplina dotada do máximo de legitimidade universitária. A isso se soma a posse dos diplomas mais elevados - agrégation e, frequentemente, doutorado -, garantia de uma carreira minimamente elevada na educação pública. Socialmente, representavam o tipo mesmo da nova intelligentsia universitária, proveniente das classes médias ascendentes e às vezes cultivadas, cuja mobilidade tornou-se possível apenas pela escola republicana, da qual eram em grande parte bolsistas - tratando-se geralmente de uma primeira geração de diplomados procedentes de meios desarraigados (muitos alsacianos). Essa ligação privilegiada com o sistema universitário parece particularmente importante para os durkheimianos 
originários dos meios sociais marginais - judeus e protestantes -, para os quais a carreira docente ofereceu uma chance única de assimilação e de recepção (sem grande discriminaçáo) nos meios majoritários. Todas essas circunstâncias deixam claro que os membros do grupo atestavam os valores ideológicos da nova Universidade e, além disso, do Estado republicano, laico e democrático. Dada a conjuntura histórica de guerra civil ainda latente que marca a virada do século, todas essas propriedades de posiçóes universitárias, sociais e ideológicas fortemente interdependentes não podiam deixar de reforçar a unidade moral e a coesão intelectual da equipe com base em interesses objetivos dos membros - rapidamente concebidos como um coletivo. Ora, ao encarnar uma nova disciplina, a emergência desse novo grupo que apresenta um grau elevado de homogeneidade e de integração intelectual contribuía, de um lado, para fazer valer as vantagens profissionais de que dispunham os membros em suas carreiras (pela solidariedade de grupo e o efeito de patronagem) e, de outro lado, colocava o problema dos recursos e da capacidade estrutural do sistema universitário estabelecido em dar lugar ao grupo enquanto promotor da nova ciência.

Sem tentar propor uma teoria da inovação no sistema universitário francês, é preciso evocar os obstáculos fundamentais à inovação temática, a saber: a formação dos professores do ensino secundário (e, consequentemente, superior) como finalidade expressa das faculdades; a unidade das carreiras secundárias e superiores; a quase inexistência de um mercado intelectual fora do ensino; enfim, o sistema de valores internos às faculdades de letras, que privilegia os temas nobres definindo-os pela "antiguidade" (fatos, autores, obras, antigos ou clássicos) e o método de abordagem "discursivo" (oposto à observação empírica) etc. Todos esses fatores eram passíveis de interditar a inserção da sociologia no programa das faculdades.

A exigência de formação de professores teve como efeito excluir todas as disciplinas que não eram matéria de ensino no secundário. Esse princípio, que representa um dos legados históricos mais importantes da Universidade do século XIX, foi posto em prática pelo sistema de exames e concursos, cuja especialização havia sido concebida exclusivamente de acordo com as necessidades de preenchimento das cadeiras de liceu - e isso até depois da Segunda Guerra Mundial. A homogeneidade das carreiras 
e a estreiteza das oportunidades em pesquisa ou em ofícios de erudição levaram, por mecanismos diferentes, mas fáceis de apreender, a canalizar tematicamente os estudos de maneira exclusiva para as disciplinas ensinadas nos liceus. Enfim, os valores universitários condenavam ao ostracismo todas as ciências aplicadas à realidade. Todas essas proposiçóes mereceriam e exigiriam um estudo aprofundado para serem aceitas, o que permitiria dar maior precisão e nitidez a seus contornos históricos, sem os quais podem prestar-se a mal-entendidos. Não obstante, elas são suficientes para demarcar as principais dificuldades encontradas pelas novas disciplinas, entre as quais a sociologia, para ingressar nas faculdades de letras na virada do século.

No entanto, as reformas universitárias do final do século levaram à admissão de uma série de inovaçóes temáticas nessas faculdades - como a geografia humana resultante do ensino de Vidal de la Blache, a história econômica, ou mesmo a história regional - que são comparáveis ao programa dos durkheimianos em muitos aspectos. Contudo, essas inovaçóes tiveram como enquadramento único as disciplinas tradicionalmente estabelecidas. Entre as novas ciências, apenas a situação da psicologia experimental e da pedagogia pode ser estritamente comparada à da sociologia. A pedagogia certamente se beneficiou diretamente das reformas realizadas desde a década de 1880, cujo principal objetivo era "profissionalizar" os estudos de nível superior, adaptando-os à demanda do mercado universitário. Instituíram-se cursos de pedagogia para racionalizar a preparaçáo dos futuros professores para suas tarefas. Nem a sociologia nem a psicologia experimental atendiam a tais necessidades, tampouco podiam se valer de tais pretextos. Além disso, nessa fase de seu desenvolvimento, ambas compartilharam a perspectiva de uma ruptura epistemológica com as filosofias reinantes na Universidade (em particular o idealismo kantiano). Se uma nova filosofia da ciência (sob o ímpeto de Boutroux) fazia crer que as disciplinas antropológicas poderiam, um dia, substituir os setores correspondentes à reflexão filosófica, ainda faltava o apoio intelectual dos filósofos para a institucionalizaçáo universitária das escolas de pensamento capazes de realizar esse projeto. Em suma, a entrada da sociologia nas faculdades das letras revelou-se ainda mais difícil à medida que a disciplina pareceu ser disfuncional em relação às funçôes tradicionais desempenhadas pelas 
faculdades, perdendo grande parte dos benefícios promocionais associados à especialização no âmbito de uma disciplina afim.

Assim se explica o caráter lento, incompleto e precário do que muitas vezes é imprudentemente qualificado como o advento do durkheimianismo na Universidade. Recordemos alguns fatos. Apesar de Durkheim ter sido encarregado, em 1887, de um curso de ciência social em Bordeaux, o conjunto dos cursos sociológicos ministrados nas faculdades de letras (considerando todos os tipos de ensino) náo passou de quatro em 1910 (Tabela 2). Durante a vida do "mestre da sociologia universitária", apenas uma cadeira foi dedicada exclusivamente à disciplina até o rescaldo da Grande Guerra, sendo o próprio Durkheim o encarregado, desde 1903, de um curso de "ciência da educação" na Sorbonne. Até a criação do regime de certificados de licence (em 1920), os cursos de sociologia não receberam nenhuma titulação específica, seja sob a forma de diploma ou de exame. Assim, é evidente que a grande maioria dos colaboradores de L'Année Sociologique tenha feito carreira nas disciplinas tradicionais ou à margem das faculdades (como Simiand, em razão de seu duplo vínculo profissional, filosófico e econômico). Durante muito tempo, acreditou-se ser necessário aceitar sem mais a ideia de que a prática da nova disciplina havia se tornado, graças ao poderoso patronato de Durkheim, uma estratégia eficaz para acelerar a carreira. No entanto, os números na Tabela 3 demonstram claramente que essa foi uma escolha fortemente penalizada com uma notável desaceleração das promoçóes - mesmo que esses dados sejam baseados em pequenas amostras (devido à insuficiência das populaçóes comparadas). Observamos que os sociólogos doutorandos (que em seguida acederam a um posto no ensino superior) defenderam suas teses, em média, quatro anos mais tarde do que seus pares nas disciplinas tradicionais. Os primeiros são nomeados para uma posição universitária na província, sendo quase oito anos mais velhos que os outros. A diferença de idade corresponde a seis anos a mais para o acesso à Sorbonne e de quatro anos a mais para a titulação na Sorbonne. Apesar de alguns durkheimianos conseguirem se colocar em boas condiçóes em um estabelecimento de erudição especializado (como Mauss e Hubert na École Pratique des Hautes Études - seção de ciências religiosas), a EPHE era uma instituição certamente marginal, particularmente em relação às faculdades, pois não preparava para nenhuma carreira. Por 
outro lado, eles não puderam ser incorporados nas principais instituições acadêmicas até os anos 1930. Nenhum instituto, laboratório ou biblioteca especializada foi criado para fins de pesquisa, e o antigo projeto de uma seção de "ciências econômica e social" da École Pratique (já previsto por Victor Duruy no momento de fundação da École) ficou abandonado (até 1947).

Portanto, é preciso reconhecer que os durkheimianos estavam longe de ter tido êxito na institucionalização universitária da sociologia. No máximo, eles conseguiram implantar sua disciplina nas margens do sistema institucional e em uma posição relegada. Embora, como universitários, eles representassem incontestavelmente a elite da corporação, seria conveniente especificar que, fazendo uso de outra linguagem, segundo os critérios posicionais objetivos do sistema de ensino, eles ocupavam uma fração dominada do grupo dominante.

Esse fracasso relativo dos durkheimianos determinou o destino da sociologia universitária até o momento, historicamente recente, em que os obstáculos estruturais à recepção da sociologia na educação superior foram removidos. Ligada ao destino do durkheimismo (que conseguiu desde o início praticamente eliminar toda competição profissional nas faculdades, exceto nas escolas de erudição), essa "pré-história" da sociologia universitária ocupa todo o período estudado.

As Tabelas 2 e 3 apresentam uma visão detalhada do desenvolvimento dos cursos e estudos em ciências sociais, considerando todas as disciplinas aparentadas à sociologia. Disso resulta claramente que, em vez de crescer, o estabelecimento dos cursos especificamente sociológicos manteve o mesmo ritmo entre 1910 e 1952, ou seja, até o início do movimento de crescimento em larga escala do sistema universitário. Observamos a precariedade das posições adquiridas pela disciplina pelo fato de o número de cursos ter sido reduzido depois de 1945 em relação ao período anterior à guerra. Essa regressão não ocorreu em nenhuma outra disciplina, com exceção da pedagogia que, sem uma sólida infraestrutura intelectual, tendeu desde a década de 1930 a ser rapidamente eliminada dos programas. Durante o mesmo período, somente a psicologia teve um crescimento contínuo de seus cursos quadruplicando em quarenta anos. É necessário associar esse fenômeno ao da reorganização do regime de estudos introduzida em 
1920 nas faculdades. A reforma da licence de filosofia, doravante composta de quatro certificados (como as outras licences que levam à agrégation), permitiu pela primeira vez dar um lugar preciso às disciplinas antropológicas no currículo filosófico. Essa reforma resultou em um duplo resultado manifesto: consagrou decisivamente o status para-filosófico da sociologia ao prescrever seu estudo e ao reservá-lo quase exclusivamente aos futuros professores de filosofia. Essa circunstância deixou marcas sobre o recrutamento intelectual de sociólogos até os dias atuais, contribuindo para retardar a emancipação da disciplina, mas também para orientar sua prática profissional em vários aspectos: o estilo dos textos, as problemáticas científicas privilegiadas, os métodos de investigação ou mesmo todo o sistema de valores internos à disciplina. Contudo, o ensino da sociologia, ao ser oficializado, foi ao mesmo tempo relegado ao rol dos cursos auxiliares menores. Enquanto a psicologia, depois da reforma, foi objeto de um diploma autônomo, concederam à sociologia apenas um meio-diploma, pois a outra metade das provas permaneceu reservada aos estudos de moral. A etnologia, por sua vez, adquiriu o direito à cidadania apenas como certificado opcional - e isso apenas na Sorbonne, excluindo-se as outras faculdades de letras - , o que desde o início limitou ao extremo a audiência universitária. Por conseguinte, vinte anos depois da introdução desse regime de estudos, é compreensível que a relação numérica entre os cursos sociológicos e psicológicos tenha variado de um para dois, enquanto os outros estudos do tipo "exótico" (etnologia, pré-história, civilizaçôes antigas e não clássicas da Europa) foram objeto apenas de cursos isolados e geralmente únicos.

Tabela 2 - As ciências sociais no ensino superior (1910-1950)

a - posiçóes de ensino nas faculdades de letras (1)

\begin{tabular}{lccccc}
\hline Disciplinas ou matérias & $\mathbf{1 9 1 0}$ & $\mathbf{1 9 2 0}$ & $\mathbf{1 9 2 9}$ & $\mathbf{1 9 3 8}$ & $\mathbf{1 9 5 2}$ \\
\hline Sociologia (2) & 4 & 5 & 5 & 7 & 6 \\
Psicologia (3) & 3 & 5 & 6 & 9 & 13 \\
Pedagogia (4) & 7 & 7 & 9 & 4 & 1 \\
Diversos (5) & - & - & 1 & 2 & 5 \\
\hline Total & $\mathbf{1 4}$ & $\mathbf{1 7}$ & $\mathbf{2 1}$ & $\mathbf{2 2}$ & $\mathbf{2 5}$ \\
\hline
\end{tabular}

Nota: Número absoluto de professores de todos os status. 
b - posiçôes nas escolas de erudição ( 1 e 6)

\begin{tabular}{lccccc}
\hline Disciplinas ou matérias & $\mathbf{1 9 1 0}$ & $\mathbf{1 9 2 0}$ & $\mathbf{1 9 2 9}$ & $\mathbf{1 9 3 8}$ & $\mathbf{1 9 5 2}$ \\
\hline Estudos para-sociológicos & 5 & 7 & 10 & 6 & 4 \\
Psicologia & 2 & 1 & 1 & 1 & - \\
Diversos & 5 & 4 & 6 & 8 & 8 \\
\hline Total & $\mathbf{1 2}$ & $\mathbf{1 2}$ & $\mathbf{1 7}$ & $\mathbf{1 5}$ & $\mathbf{1 2}$ \\
\hline
\end{tabular}

Notas: I. Número absoluto de professores de todos os status.

2. Incluidas: "ciência social", "pedagogia e sociologia", "filosofia social", "história da economia social".

3. Incluidas: "psicologia da criança", "psicologia pedagógica".

4. Incluidas: "ciência da educação", "pedagogia prática", "filosofia pedagógica".

5. Incluidas: "etnologia", "etnografia", "história as religiões (primitivas)", "línguas e literaturas célticas".

6. Collège de France e seção 4 e 5 da École Pratique des Hautes Études. Incluída "história o trabalho", "história os fatos e doutrinas econômicas", "sociologia e sociografia muçulmana", "fatos econômicos

e sociais", "previdência e assistência social", "ensino da cooperação", "história das ideias morais", "história e estatísticas econômicas".

\section{Tabela 3 - Idade de acesso às principais posições universitárias de acordo com a disciplina}

\begin{tabular}{lccccc}
\hline Disciplina ministrada & Doutorado & \multicolumn{2}{c}{ Faculdade de província } & \multicolumn{2}{c}{ Sorbonne } \\
\cline { 3 - 6 } & em Lettres & $\begin{array}{c}\text { Maître de } \\
\text { conférence }\end{array}$ & $\begin{array}{c}\text { Professor } \\
\text { titular }\end{array}$ & $\begin{array}{c}\text { Maître de } \\
\text { conférence }\end{array}$ & $\begin{array}{c}\text { Professor } \\
\text { titular }\end{array}$ \\
\hline Sociologia (1) & 34,3 & 34,6 & 40,8 & 42,6 & 52,8 \\
Filosofia (2) & 31,0 & - & - & 37,8 & 49,0 \\
Letras clássicas (2) & 30,2 & - & - & 31,3 & 45,8 \\
História (2) & 30,4 & 26,4 & 32,0 & 39,5 & 49,8 \\
Geografia (2) & 29,2 & - & - & 34,2 & 48,6 \\
Total sem a sociologia (2) & 30,3 & 26,9 & 31,5 & 35,6 & 48,6 \\
Seção de ciências & $41,8(4)$ & & & $36,6(3)$ & \\
religiosas, EPHE & & & & & \\
\hline
\end{tabular}

Notas: I. Trata-se de Durkheim, Bouglé, Espinas, Fauconnet, Halbwachs, Davy, e Richard.

2. Professores titulares da Sorbonne, ativos entre 1900 e 1910.

3. Nomeação para posto titular de maître de conférence ou de directeur d'études ${ }^{16}$.

4. Havia apenas 6 doutores entre os 17 professores em 1905.

15 Professores pesquisadores concursados que compõem um dos escalöes do corpo professoral na França. No século XIX, a designação referia-se mais especificamente àqueles que ministravam cursos em pequenos grupos (N.T.).

16 Professores pesquisadores vinculados a instituições de pesquisa e responsáveis pelo oferecimento de seminários. (N.T.). 
Encontramos um quadro muito diferente do desenvolvimento desses cursos nos estabelecimentos de erudição (École Pratique des Hautes Études, Collège de France - ver Tabela 2), devido à ausência da pedagogia e da escassez dos cursos de psicologia. Nesse caso, depois de um crescimento aparentemente contínuo até os anos 1920, é notável que os cursos para-sociológicos (sobretudo de ordem histórica e econômica) acusam um declínio notável, que em 1952 cai abaixo do nível de antes da Primeira Guerra. Apenas as disciplinas marginais e exóticas progridem um pouco ao longo do tempo, tendo em vista que são tipos variados de erudição que no conjunto não formam um sistema.

$\mathrm{Na}$ Tabela 4 observa-se que o crescimento do número de teses de interesse diretamente sociológico, depois de momento próspero no final do século, rapidamente deu lugar à estagnação durante um longo período, com fortes oscilaçóes conjunturais de uma década à outra. Ocorre exatamente o mesmo com as outras ciências humanas (pedagogia e psicologia), que ainda aqui compartilham um destino semelhante. Acrescente-se que a geografia humana e econômica - disciplina que se estabeleceu no sistema universitário na mesma época que a sociologia e que por um momento parecia claramente afim a ela (ao ponto de essa última, sob a forma da "morfologia social" durkheimiana, poder contestar seu objeto e, assim, pôr em questão sua identidade) - teve o mesmo tipo de oscilação em torno de um baixo número médio de teses. Quanto à "moral" - disciplina filosófica que serviu durante a maior parte do século XIX de razão social para a reflexão sociológica -, sua marginalidade nos trabalhos universitários se acentuava independentemente do fato de seu ensino ter sido formalizado nas faculdades de letras sob o título de um meio-diploma de licence. De maneira geral, a introdução de cursos novos nas faculdades não parece ter afetado diretamente a produçáo de teses - salvo, talvez, no início dos movimentos de institucionalização, quando a esperança de novas carreiras, exceção feita às efetivamente oferecidas, provocou algumas conversóes temáticas na escolha dos temas de tese. Essa relativa independência entre o número de cursos instituídos e o número de doutorados se explica pela persistente estreiteza do mercado universitário especializado, bem como pela relativa facilidade de reconversão depois da defesa - sob a condição de se visar uma cadeira no amplo espectro da disciplina de origem. 


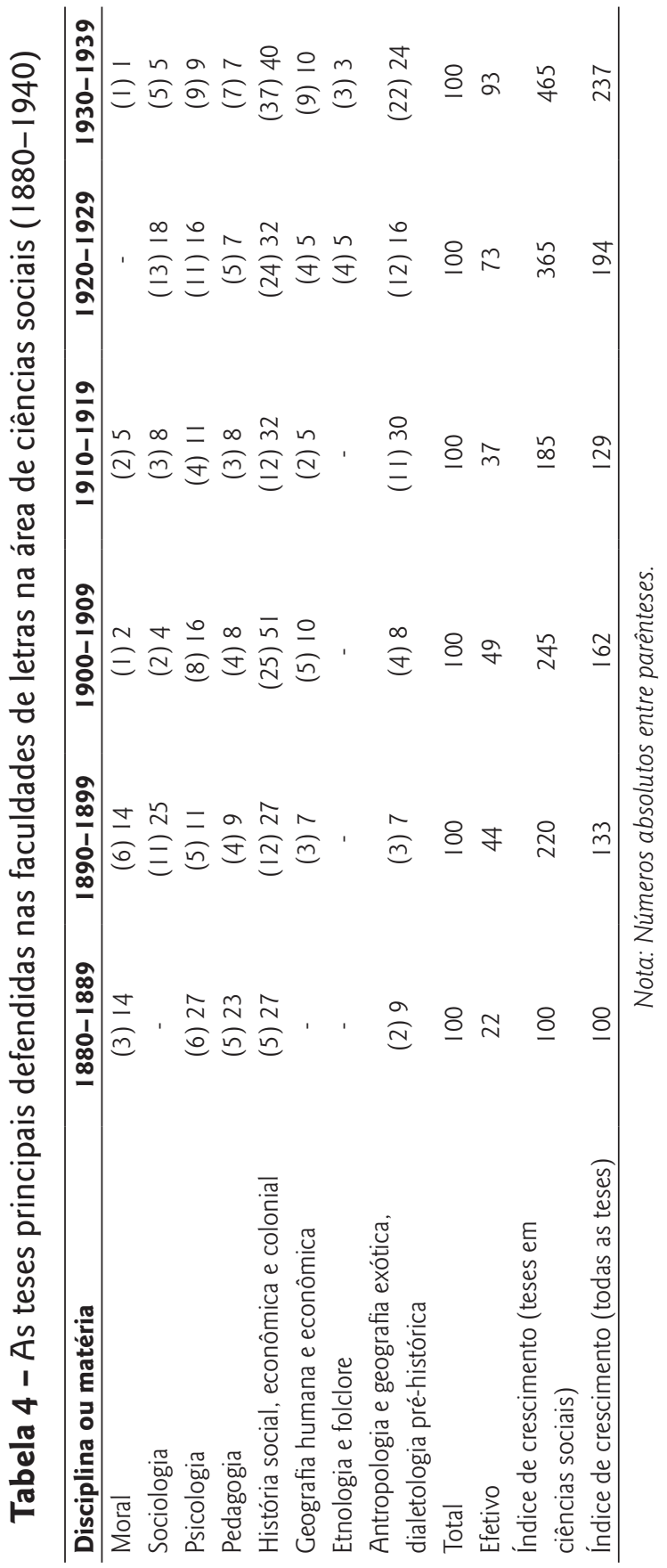


O alcance e a amplitude da estagnação que afeta as vocaçóes doutorais nas ciências para-sociológicas encontra sua medida indireta no progresso constante, excetuando-se no período da Guerra, do efetivo de doutorandos em outras disciplinas (ver última linha da Tabela 4) e no crescimento ainda maior do número de teses defendidas em matérias próximas à sociologia, mas pertencentes a disciplinas clássicas (história social, geografia exótica etc.). Embora o conjunto das "ciências sociais", no sentido amplo, acusa um aumento anual no número de doutores de um a quase cinco em um período de 40 anos, as únicas responsáveis por isso são as disciplinas clássicas. (As teses da história social aumentaram seis vezes durante esse período, assim como as teses da geografia). Finalmente, verificamos, de um lado, que as publicaçóes universitárias refletem globalmente a reestruturação temática do campo dos estudos sociais e, de outro lado, o crescimento de seu peso específico no sistema das disciplinas. Mas, desse modo, eles manifestam um fato fundamental: a introdução desses estudos não perturbou de modo algum o sistema de disciplinas estabelecido no século XIX - nem em seu sistema de valores (hierarquia das disciplinas), nem em sua finalidade ou em suas funçôes. Pelo contrário, a expansão diferencial dos escritos acadêmicos de interesse sociológico mostra claramente como o ensino superior conseguiu, de uma só vez, integrar em seu seio o movimento de transformação das disciplinas da faculdade de letras pela sociologia (poderíamos falar de "sociologização") - que é, sem nenhuma dúvida, o maior fato epistemológico do último meio século -, canalizando-as e camuflando-as para manter sua integridade institucional e evitar qualquer mutação funcional. Assim, o essencial da inovação temática pôde ser devidamente recuperado, ou seja, constrangido a ajustar-se aos quadros intelectuais das disciplinas estabelecidas, tais como a história e a geografia - as quais viram inflar seus efetivos universitários. O sucesso da modernização da história e da geografia, graças à revolução epistemológica que as havia fecundado, desde os anos 1890, não fez mais do que assegurar um acréscimo de legitimidade às ciências acadêmicas anteriormente pouco praticadas na Universidade (geografia) ou comprometidas com uma retórica formalista difusa (história). Sua transformação em ciência explicativa, de acordo com o espírito da nova Sorbonne, contribuiu para a legitimação do sistema universitário clássico que lhes permitiu essa evolução. A admissão de 
novas disciplinas (sociologia, pedagogia, psicologia) à margem do sistema - isto é, em posiçóes dominadas (pelas disciplinas clássicas) e sem qualquer possibilidade previsível de desenvolvimento - não teve outra função. O sistema estabelecido reforçou-se e evitou sua expansão e transformação em sistema, simplesmente atribuindo para si o prestígio intelectual das novas disciplinas, dotadas de um alto coeficiente de inovação epistemológica, mediante a concessão de algumas cadeiras aos protagonistas mais brilhantes e submetendo-as às exigências do antigo regime de estudos (integração nas estruturas escolares da filosofia ou da história) - o que as desviou parcialmente da vocação de ciência empírica ou experimental.

\section{Conclusão}

A investigação estabeleceu que os durkheimianos eram os únicos, dentre todas as escolas de pensamento sociológicas, a possuir as propriedades escolares, sociais e intelectuais necessárias para a sua admissão nas faculdades de letras. Os outros grupos, mais ou menos ligados às faculdades de direito, públicas ou privadas, não podiam aspirar à institucionalização universitária de suas disciplinas em razão dos valores pragmáticos que prevaleciam nessas faculdades, bem como da pregnância das disciplinas sociais que estavam estabelecidas desde o século XIX (economia política, direito constitucional etc.) - em relação às quais sua contribuição específica não oferecia nada de original. Poderíamos mostrar que as mesmas propriedades de condição intelectual e de posição no sistema de classes facilitaram a integração dos representantes dos grupos concorrentes no ensino para universitário (École Libre des Sciences Politiques, École d'Anthropologie, Collège Libre des Sciences Sociales), o que consagrou sua marginalidade no seio mesmo do movimento sociológico. Apesar da sociologia universitária ter se identificado quase exclusivamente com a Escola Francesa de Sociologia, que a impôs às faculdades de letras, o status da disciplina permaneceu marginal ou mesmo precário na sistema ensino até os anos 1950 (incluído). A despeito de todas as aparências e ilusóes retrospectivas, isso se deu em razão da resistência propriamente estrutural que o sistema estabelecido de disciplinas opôs, com sucesso, às mudanças de função que teriam provocado a integração massiva de disciplinas sociais autônomas. O "declínio" repetidamente descrito (embora problemático) da Escola 
durkheimiana entre as duas guerras não pode ser reduzido a qualquer transformação hipotética do "clima do Quartier latin" (que, por sua vez, teria que ser explicado), ou simplesmente ao "epigonismo" (totalmente duvidoso) dos alunos sobreviventes do falecido mestre, ou ainda, o que é equivalente, à hecatombe da guerra que havia atingido os jovens durkheimianos. Ao contrário, esse "declínio" resultou da rigidez efetiva do sistema universitário diante da inovação temática; rigidez suficiente para desencorajar as vocaçóes das novas disciplinas ou desviá-las de sua finalidade específica em favor do sistema.

\section{Referências}

CLARK, T. N. Prophets and Patrons: The French University and the emergence of the Social Sciences. Cambridge: Harward University Press, 1973.

GIDE, C. L'enseignement des sciences sociales en France, enseignement supérieur. In: Congrés international de l'enseignement des sciences sociales. Paris: Chevalier-Marescq, 1902.

HAURIOU, M. Les facultés du droit et la sociologie. Revue Générale de Droit, Paris: BergerLevrault, v. 8, 34 p., 1893.

\section{Sociologists Before the 1950s}

\section{Abstract}

The aim of this article is to analyse the social stratification of the practitioners in sociology in France until the 1950s and, beyond, to search the reasons that have maintained sociology in a marginal status in the French university system during this period. First, I consider the Durkheimian School and present the data that explain the reason of its success in the rivalry with other practitioners in the discipline. Second, I argue that the Durkheimians occupied a dominated position inside the dominant group and, because of that, they could not subvert the rules of the French university system. On the contrary, they were assimilated by it and were submitted to play a role relegated to relation to the traditional stablished disciplines.

Keywords: French sociology. Durkheimian school. French university system. 